\title{
ELECTROANTENNOGRAM RESPONSE OF THE COCONUT PEST, RHYNCHOPHORUS FERRUGINEUS (COLEOPTERA:CURCULIONIDAE) TO ALCOHOLS
}

NEELAKANTHI E. GUNAWARDENA

Department of Chemistry, University of Kelaniya, Kelaniya.

\section{AND}

\section{F. KERN}

Institute of Organic Chemistry, The University of Erlangen - Numberg 42, Henke Strasse, 8520, Erlangen, Germany.

\author{
(Date of receipt : 21 May 1993) \\ (Date of acceptance : 27 December 1993)
}

\begin{abstract}
The coconut pest Rhynchophorus ferrugineus F., shows short range attraction to coconut sap, whose volatile constituents consist mainly of short chain alcohols. In this study, electrophysiological responses of male and female antennae to four alcohols in coconut sap, viz. ethyl, n- propyl, $n$ - butyl and n-pentyl alcohols were recorded. Pentanol, which constitutes a major portion of the coconut sap elicited the greatest response in the antennae of both male and female $i R$. ferrugineus $\left(\mathrm{EAG} / \mathrm{EAG}_{\max }=0.85 \mathrm{SD}, \pm 0.16\right.$ ) and this response was significantly different from that of the control as well as those of the ethanol and n-butanol (EAG/EAG $G_{\max }$ $=0.24$ and 0.32 respectively). n-Propanol also had high EAG potency with $\mathrm{EAG} / \mathrm{EAG}_{\max }=0.52, \mathrm{SD} \pm 0.15$ which was significantly not different $(\mathrm{P}>0.05$ ANOVA, Scheffe's test) from that of n-pentanol.
\end{abstract}

To compare the activities of the above alcohols with $C_{6}$ to $C_{10}$ n-alcohol, EAGs of hexanol upto decanol were also recorded under the similar conditions. Results showed that the activity of pentanol was still the highest in the series, while that of hexanol (EAG/EAG ${ }_{\max } 0.83, S D \pm 0.16$ ) was not significantly different from it. Heptanol elicited moderate activity $\left(E A G / E A G_{\max }=0.52, S D \pm 0.15\right)$ which did not differ significantly from those of propanol, pentanol and hexanol. Other alcohols at the higher end of this series viz.octanol and nonanol had lesser EAG potencies $\left(\mathrm{EAG} / \mathrm{EAG}_{\max }=0.35, \mathrm{SD} \pm 0.13\right.$ and $0.25, \mathrm{SD} \pm 0.09$. respectively) which were not significantly different from that of the control $\left(E A G / E A G_{\max }=0.16, S D \pm 0.06\right.$ ). The lowest $E A G$ response of $E A G / E A G_{\max }=0.19(S D \pm 0.05)$ was shown by decanol and this response was also close to that of the control.

Key words: Rhynchophorusferrugineus, red weevil, coconut pest, EAG assay, alcohols.

\section{INTROQDUCTION}

Many insects rely largely on semiochemicals for host seeking behaviour. ${ }^{1}$ In this respect, Coleopterans have been lately subjected to intensive studies. ${ }^{2}$ Host attractants usually are multicomponent, constituting simple aromatics, terpenes, aliphatic alcohols and such other compounds. ${ }^{3}$ The screening of compounds for semiochemicals has been of great interest in the recent years, ${ }^{4,5}$ with the goal of 
developing chemical formulations that can attract pests under field conditions. Rapid screening of compounds has been facilitated by the electroantennogram $(E A G)^{6}$ technique which records the changes in electrical potential occurring between the base and the tip of an antenna as a result of chemical stimuli .

Rhynchophoris ferrugineus, F. (Coleoptera: Curculionidae) commonly known as the red weevil, is a major pest on the coconut palm in Sri Lanka. ${ }^{7}$ Behavioural studies have shown this pest to be strongly attracted to the coconut sap. ${ }^{8}$ Fermenting coconut sap is reported to consist of several lower alcohols ${ }^{9}$ and this sap is also a suspected natural attractant for the red weevil. Accordingly, the investigations on the receptor sensitivity of this pest to the four constituent alcohols in coconut sap was undertaken using EAG technology. The findings improve the understanding of the olfactory basis of the host finding behaviour of $R$. fermugineus. Chemical ecological studies of this nature are important for formulating artificial attractants for $R$. fernigineus, whose detection in the field has become extremely difficult. ${ }^{10}$

\section{METHODS AND MATERIALS}

Chemicals: Source and gas chromatographic purity of chemicals subjected to EAG assay are listed in Table 1. Hexane (Analar) was purchased from Merck Chemical Co. Germany. Neat liquids of each test substance $(1 \mu \mathrm{l})$ were put onto filter paper strips $(20 \times 7 \mathrm{~mm}$ ) which were already placed inside glass cartridges ( $54 \mathrm{~mm}$ long, 7 $\mathrm{mm}$ ID). These test substances were used immediately in the EAG assay. A blank was prepared using $1 \mu \mathrm{l}$ of hexane.

EAG assay: Newly emerged adult $R$. ferrugineus aged between 1-5 days were air lifted from Sri Lanka to Germany. They were maintained in a laboratory with a photoperiod regime of $10 \mathrm{~h}$ light $14 \mathrm{~h}$ dark at $25 \pm 2^{0} \mathrm{C}$ and were fed with apples and water. One weevil (age 3-8 days) was anesthetized with a stream of $\mathrm{CO}_{2}$, the antenna cut immediately as close to the base as possible, and isolated. Following the methodology originally described by Schneider ${ }^{6}$ this antenna was fixed on two $\mathrm{Ag}-\mathrm{AgCl}$ electrodes which were placed in glass capillary tubes filled with insect Ringer's solution. ${ }^{11}$ The recording electrode was inserted into the antennal club and the indifferent electrode was inserted into the base of the antenna (Fig. 1). In order to prevent leakage of receptor lymph and the subsequent drying up of the antenna, both ends of the antenna were sealed with vaseline. Total time of mounting did not exceed $10 \mathrm{~min}$. Chemical stimuli were delivered as $1 \mu$ l aliquots on a filter paper strip which was placed inside glass cartridges, oriented towards the antennal preparation from ca. $1 \mathrm{~cm}$. A stream of air filtered through a charcoal filter $(0.5 \mathrm{l} / \mathrm{min})$ was purged through the cartridge for 1 sec. A vacuum outlet was already positioned approximately $10 \mathrm{~cm}$ behind the setting of the antenna in order to remove attractant-containing air from the area surrounding the antenna. The stream of filtered air continuously bathed the antenna except during the time that the stimulus was sent. At least 3 min elapsed between stimulations to allow for adequate receptor 


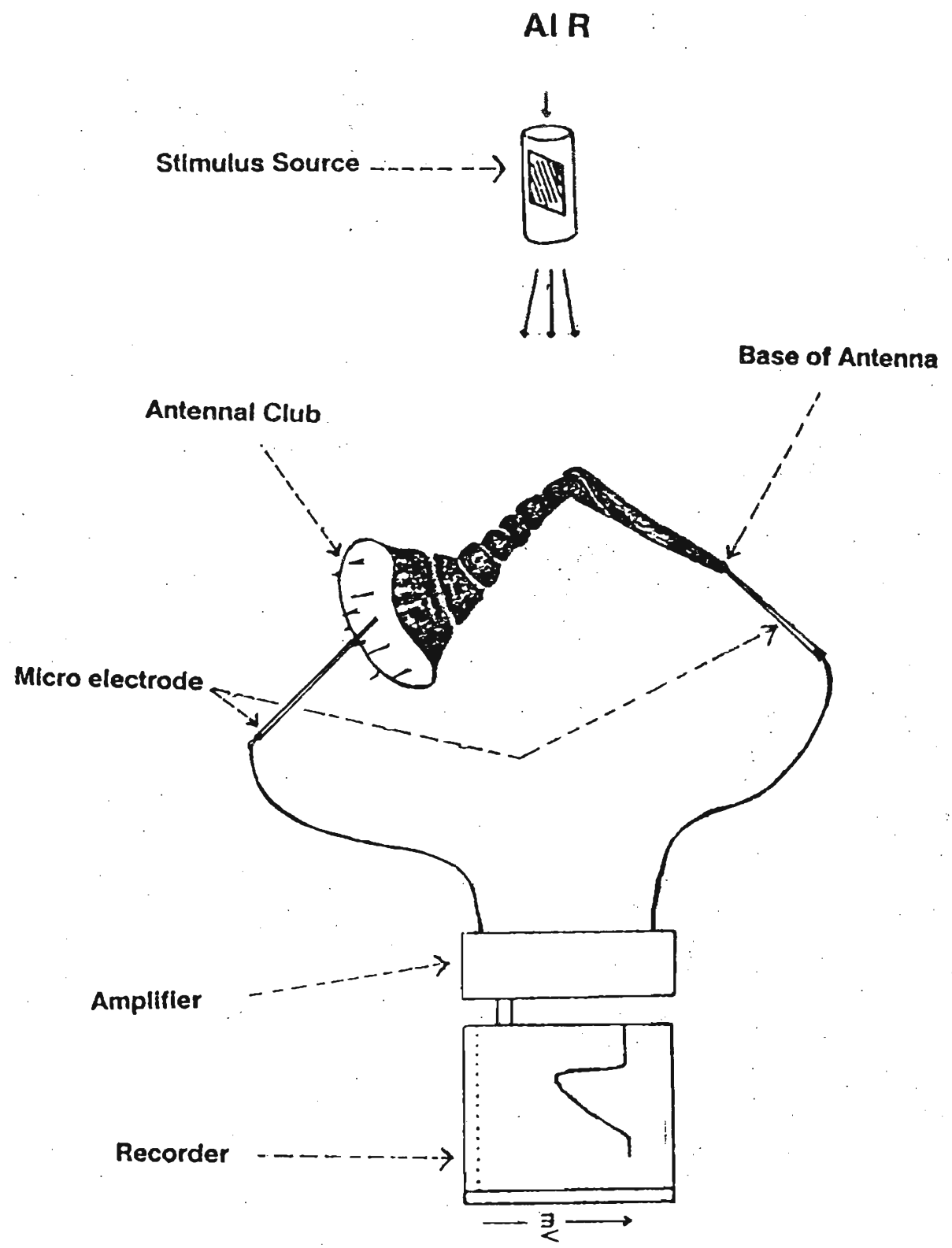

Figure 1: Diagramatic representation of $R$. ferrugineus antenna and the positions of micro electrodes in the E$\Lambda G$ experiment. 
recovery. The responses of the antenna to test compounds were recorded as peaks and the distance between the base of the peak and the highest point was measured. The hexane solvent was used as the control (see, later). Test compounds were presented to the antenna on a random basis. Each compound was assayed on both male and female antennae. The life-time of an isolated $R$. ferngineus antenna was approximately $30 \mathrm{~min}$ and therefore a total of 6 (male and female) antennae were used. Each test compound was presented to the antenna 6 times and so was the control. All test odour responses accompanying each control response were considered one set of data. In each set of data, the highest response was taken as 1 and all other values were converted to fractions. This method permitted comparison within and between the series because the individual and time dependent alterations in responses were taken into consideration. All comparisons of mean EAG responses of $R$. ferrugineus were done by the use of (ANOVA), Scheffe's test unless otherwise stated.

Table 1: Source and purity of semiochemicals used in the EAG assay.

\begin{tabular}{|c|c|c|}
\hline Compound & Source of supply & Chemical purity* (\%) \\
\hline 1) Ethanol & Aldrich Chemical Co. & 99 \\
\hline n-Propylalcohol & Aldrich Chemical Co. & 99 \\
\hline n-Butanol & Aldrich Chemical Co. & 99 \\
\hline 4) n-Pentanol & Aldrich Chemical Co. & 99 \\
\hline n-Hexanol & Fluka Chemicals, Germany & 99 \\
\hline n-Heptanol & Fluka Chemicals, Germany & 97.5 \\
\hline n-Octanol & Sigma Chemicals GMBH & 98 \\
\hline n-Nonanol & Sigma Chemicals GMBH. & 99 \\
\hline n-Decanol & Sigma Chemicals GMBH & 98 \\
\hline
\end{tabular}

Determined by GLC analysis.

\section{RESULTS}

The mean responses of male and female $R$. fernigineus for the control did not differ significantly $\left(P<0.05\right.$, Student's t-test) $\left(E A G / E A G_{\max }=0.18, S D \pm 0.08\right.$ and 0.15 , $\mathrm{SD} \pm 0.041$ respectively ) and therefore, the data were combined for analysis. The EAG activities of the volatile constituents in the coconut sap are presented in Figure 2.

Except that of n-pentanol all other responses elicited by the above alcohol constituents were not significantly different $(P>0.05)$ from that of the control. The highest $E A G$ activity was seen in n-pentanol $\left(E A G / E A G_{\max }=0.85, S D \pm 0.16\right)$ and this was significantly different $(P<0.05)$, from those of ethyl alcohol and $n$-butanol $\left(E A G / E A G_{\max }=0.24\right.$ and 0.32 respectively). $n$-Propanol also elicited high EAG 


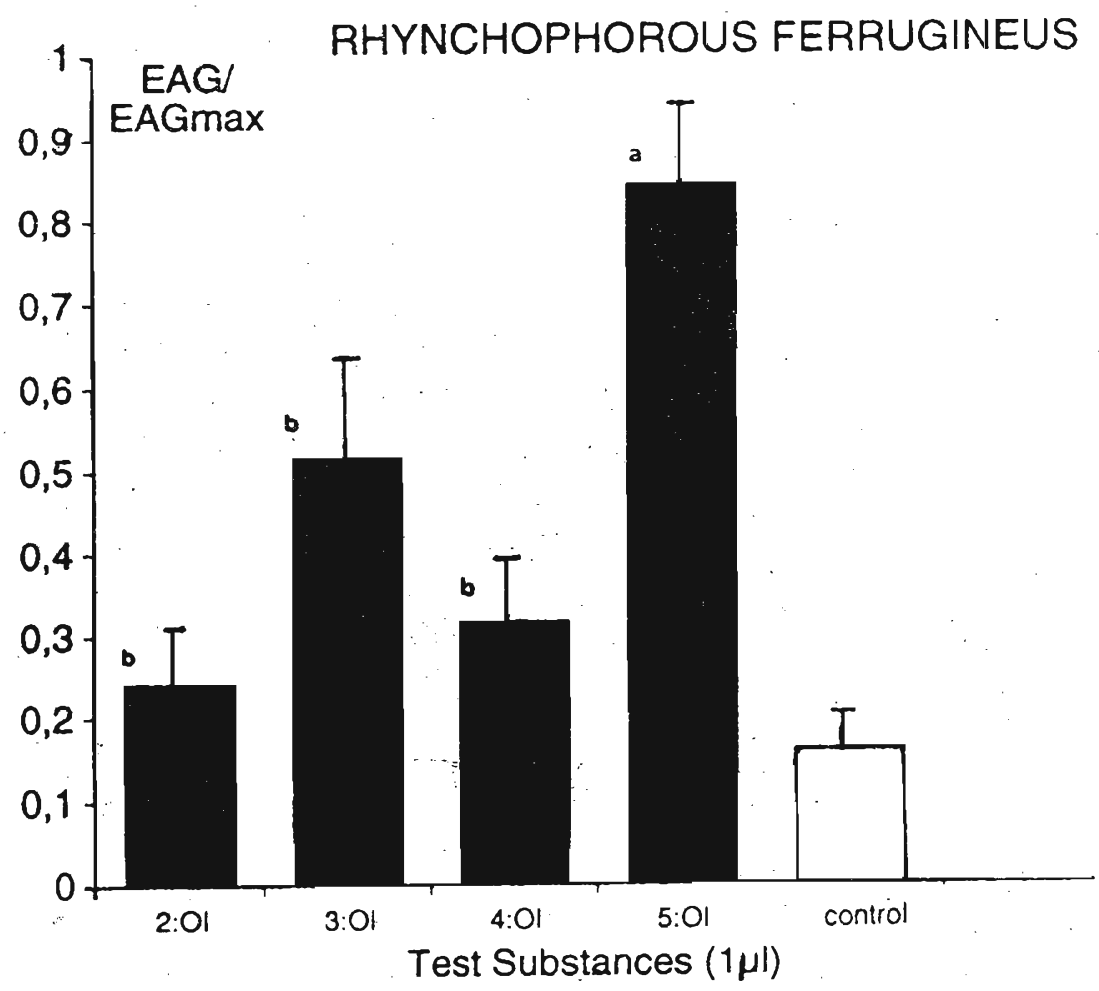

Figure 2: Electroantennogram responses of $\boldsymbol{R}$. ferrugineus antenna to the four alcohol constituents in the coconut sap.

Verticle bars indicate standard deviation. Means not followed by the same small letter are significantly different ( $P<0.05$, ANOVA, Scheffe's test).

2: 01 = Ethyl alsohol, $3: 01$ propyl alcohol etc.

potency $\left(E A G / E A G_{\max }=0.52, S D \pm 0.15\right)$ and this was not significantly different from that of n-pentanol.

EAG profile of the entire alcohol series is shown in Figure 3. n-Pentanol elicited the highest response in the series while that of hexanol was not significantly different from it $\left(E A G / E A G_{\max }=0.83, S D \pm 0.16\right)$. n-Heptanol showed moderate activity of $E A G / E A G_{\max }=0.52, S D \pm 0.15$ which was not significantly different $(P>0.05)$ from that of $n$-propanol, but was significantly different $(P<0.05)$ from those of pentanol and hexanol: The activities elicited by higher members of the series, n-octanol $\left(E A G / E A G_{\max }=0.35, S D \pm 0.13\right), n$-nonanol $\left(E A G / E A G_{\max }=0.25, S D\right.$ $\pm 0.08)$, n-decanol $\left(\mathrm{EAG} / \mathrm{EAG}_{\max }=0.19, \mathrm{SD} \pm 0.05\right)$ were low and were not significantly different $(P>0.05)$ from those of the ethanol $\left(E A G / E A G_{\max }=0.24\right)$ and $n$-butanol $\left(E A G / E A G_{\max }=0.32\right)$ as well as from that of the control $\left(\mathrm{EAG} / \mathrm{EAG}_{\max }=0.16\right)$. 


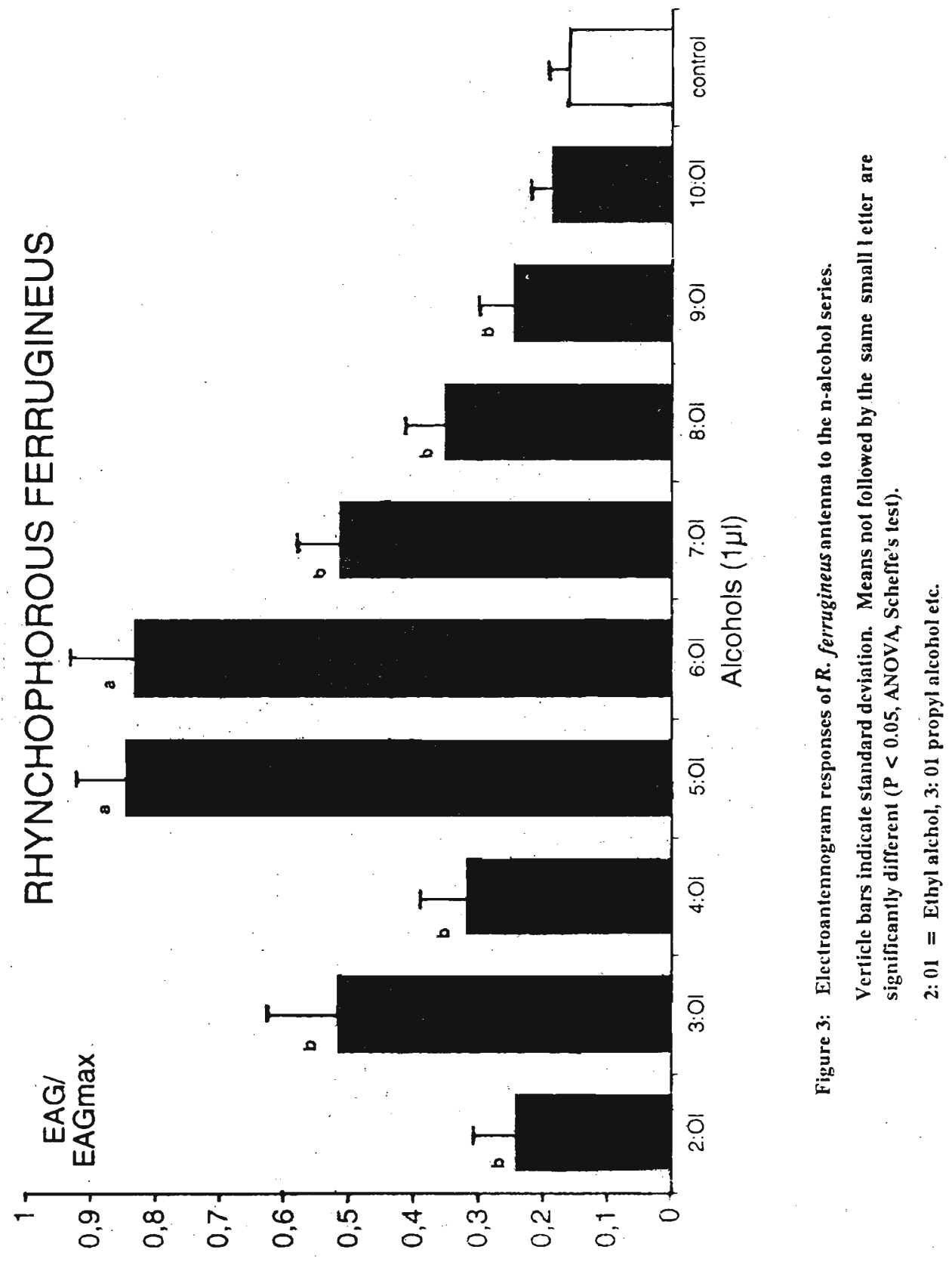




\section{DISCUSSION}

In the coconut tapping areas of Sri Lanka, insects such as bees, beetles and weevils are normally found trapped in the pots containing fermenting coconut sap. Among these insects red weevils are known to constitute a fair proportion although no accurate numbers are available (Gunawardena N.E., unpublished data). Whether this natural trapping of red weevils is due to chance or to the presence of a genuine attractant in the coconut sap is not known.

EAG comparisons of potential semiochemicals are a prerequisite in the process of formulation of baits ${ }^{4}$. The best candidates for such comparative EAG studies are those possessing a narrow range of volatility. However, valid relative comparisons in potency of EAGs are possible between compounds if the compound with a lower volatility (i.e. far fewer number of molecules per stimulation puff) elicits EAG responses of equal or greater magnitude than those elicited by the compound with higher volatility (i.e. far greater numbers of molecules per stimulation puff). It is possible then, to conclude that the less volatile compound is superior to the more volatile compound, because the EAG magnitude per molecule delivered was proportionately greater.

Considering the above arguments, if only the volatility factor is important, a gradual decrease in the EAG responses is expected for the alcohol series. However the observed EAG profile is entirely different from the expected and it is clear that in this EAG comparison high receptor sensitivities have overrided other factors such as volatility.

The greater antennal responsiveness to the saturated C-6 alcohols, and monounsaturated aldehydes has been reported for some insects, e.g. Colorado potato beetle, Leptinotarsa decemlineata Say ${ }^{12}$ and the boll weevil, Anthonomus grandis Boh. ${ }^{13}$ High activity of C-5 saturated alcohols have been rare although a recent EAG study revealed that Trirhabda bacharides (Coleoptera: Chrysomelidae) showed highest activity for C-5 and the second highest for C- 6 alcohol in the series ${ }^{14}$. High antennal receptor sensitivity to pentanol and hexanol was observed for $R$. ferrugineus. This is interesting because pentanol is the most abundant constituent among the volatiles of the coconut sap. Among other volatiles of the coconut sap are acetaldehyde, ethyl acetate, ethyl lactate and 3-ethoxy propanal whose EAG activities have not been assayed. It is difficult to assume that the receptor sensitivity of $R$. fernigineus to the coconut sap derives entirely from alcohols. However, it is probable that C-5 alcohol in the coconut sap plays an important role in its high activity. This result is also in total agreement with the results of our previously published $^{8}$ behavioural bioassay where C-5 alcohol showed the highest activity compared to the other alcohols assayed namely, ethyl alcohol and isopropyl alcohol. 


\section{Acknowledgement}

The authors thanks Alexander von Humboldt Foundation, Germany for the fellowship to NEG, Prof. H.J.Bestmann of the Institute of Organic chemistry, Erlangen, Germany for analytical facilities. International Foundation for Science, Sweden is thanked for the research grant (F-936-2) and Mr H.M.W.K.B.Herath of University of Kelaniya for the supply of red weevils.

\section{References}

1. Miller J.R. \& Strickler. K.L. (1984). Finding and accepting host plants. In Chemical Ecology of Insècts, (Eds. W.J. Bell \& R.T. Carde), pp. 127 -157. Sinauer Associates, Inc. Sunderland, MA.

2. Vitae' J.P. \& Francke W. (1976). The aggregarion pheromones of bark beetles: Progress and problems, Naturwissenschaften 63: 550-555.

3. Dickens J.C. (1990). Specialized receptor neurons for pheromones and host plant odors in the boll weevil, Anthonomus grandis Boh. (Coleoptera: Curculionidae), Chemical Senses 15(3):311-331.

4. Salmon S.M., Birgersson G., Payne T.L. \& Berisford C.W. (1991). Electroantennogram responses of the southern pine beetle parasitoid, Dinotiscus dendroctoni (Ashmead) (Hymenoptera: Pteromalidae) to potential semiochemicals, Journal of Chemical Ecology 17(12): 2527-2538.

5. Light D.M., Kamm J.A. \& Buttery R.G. (1992). Electroantennogram responses of alfalfa seed chalcid, Bntchophagus roddi (Hymenoptera: Eurytomidae) to host and non- host plant volatiles, Joumal of Chemical Ecology 18(3): 333-352.

6. Schneider D. (1957). Elektrophysiologische untersuchugen von chemo und mechanorezeptoren der antenne des seidenspinnere Bombyx mori L, Zeitschrift fur vergleichender Physiologie 40: 8-41.

7. Pinto J.L.J.G., (1984). Red weevil. In Coconut Bulletin, Coconut Board of Sri Lanka, 1(2):36.

8. Gunawardena N.E., \& Gunatilake R. (1993). Preliminary studies on a host attractant of the coconut pest, Rhynchophonis fernigineus, (Coleoptera:Curculionidae) Joumal of the National Science Council of Lanka 21(1):93-101.

9. Samarajeeva U. \& Adams M.A. (1983). Biochemistry of frementation in toddy and production of Arrack, Vidyodaya Joumal of Arts and Science Letters 11(1\&2):41-53.

10. Estate management and pest control, Advisory leaflet, No.37 and 50, Coconut Research Institute, Lunuwila, Sri Lanka. 
11. Barbosa P. (1974). Manual of basic techniques in insect histology, pp. 240. Autumn Publishers, Amherst, Massachusetts.

12. Visser J.H: (1979). Electroantennogram responses of the Colorado beetle, Leptinotarsa decemlineata to plant volatiles. Entomologia Expermenatalis et Applicata 25:86-97.

13. Dickens J.C. (1984). Olfaction in boll weevil, Anthonomus grandis Boh. (Coleoptera: Curculionidae): Electroantennogram studies, Joumal of Chemical Ecology 10:1759-1785.

14. Dickens J.C. \& Boldt P.E. (1985). Electroantennogram responses of Trihabda bacharides (Weber) (Coleoptera: Chrysomelidae) to plant volatiles, Joumal of Chemical Ecology 11:767-779. 